nephron

Practice

\title{
UK Renal Registry 17th Annual Report: Chapter 11 Centre Variation in Access to Renal Transplantation in the UK (2008-2010)
}

\author{
Rishi Pruthi ${ }^{a}$, Elinor Curnow ${ }^{b}$, Paul Roderick $^{c}$, Rommel Ravanan ${ }^{d}$

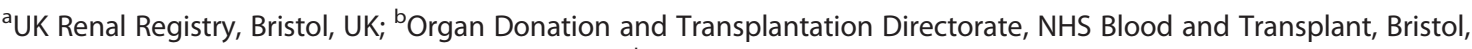

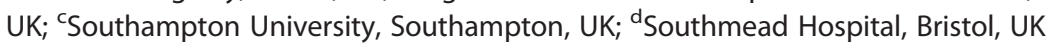

\section{Key Words}

Centre variation $\cdot$ Comorbidity $\cdot$ Donor after brainstem death - Donor after cardiac death · Equity of access · Living kidney donor - Outcomes - Patient factors - Quality improvement . Renal transplantation - Transplant waiting list

\section{Abstract \\ Background: Renal transplantation is recognised as being the optimal treatment modality for many patients with established renal failure. This analysis aimed to explore inter-centre variation in access to renal transplantation in the UK. Methods: Transplant activity and waiting list data were obtained from NHS Blood and Transplant, demo- graphic and laboratory data were obtained from the UK Renal Registry. All incident RRT patients starting treatment between 1st January 2008 and 31st December 2010 from}

71 renal centres were considered for inclusion. The cohort was followed until 31st December 2012 (or until transplantation or death, whichever was earliest). Results: Age, ethnicity and primary renal diagnosis were associated with both accessing the kidney transplant waiting list and receiving a kidney transplant. A patient starting dialysis in a non-transplanting renal centre was less likely to be registered for transplantation (OR $0.74,95 \% \mathrm{Cl} 0.68-0.81$ ) or receive a transplant from a donor after cardiac death or a living kidney donor (OR 0.75, 95\% Cl 0.67-0.84) compared with patients cared for in transplanting renal centres. Once registered for kidney transplantation, patients in both transplanting and non-transplanting renal centres had an equal chance of receiving a transplant from a donor after brainstem death (OR $0.93,95 \% \mathrm{Cl} 0.78$ to 1.10 ). Conclusion: There was wide variation in access to kidney transplantation between UK renal centres which cannot be explained by differences in case mix.
Email: renalregistry@renalregistry.nhs.uk 


\section{Introduction}

For 'suitable' patients with established renal failure, renal transplantation confers both better quality of life and life expectancy than dialysis [1-3] and is the preferred modality of renal replacement therapy. Achieving prompt and timely activation on the waiting list is important not least because increasing length of time on dialysis adversely affects graft and patient survival, but also because the current organ allocation algorithm introduced in April 2006 takes time spent on the waiting list into account when allocating deceased donor kidneys in the UK [4]. Thus, centres that achieve earlier listing for transplantation provide an advantage for their patients compared with centres that take longer.

This analysis aims to evaluate whether equity of access to the renal transplant list exists for patients with end stage renal disease across the UK, whether centres differ in the time taken to activate suitable patients on the waiting list and whether equity exists in the receipt of a renal transplant once the patient is on the transplant list (that is, the conversion efficiency from being on the waiting list to receiving a transplant). Patient specific and independent variables that influenced access to the waiting list or transplantation were analysed.

\section{Methods}

\section{Study population}

All adult patients starting renal replacement therapy $(N=20,076)$ between 1st January 2008 and 31st December 2010 in renal centres $(N=71)$ returning data to the UK Renal Registry (UKRR) were considered for inclusion. For the analysis of the proportion of a centre's patients included on the waiting list, patients aged 65 years or above $(n=9,908)$, patients with inappropriate activation and early suspension as described below $(n=55)$ and patients listed for multi-organ transplants other than pancreas $(n=34)$ were excluded, resulting in a final cohort of 10,079 patients. These patients were followed to 31st December 2012 or until they were put on the waiting list for kidney transplant alone, kidney plus pancreas transplant, or death, whichever was earliest. For the analysis of the proportion transplanted, all patients from the incident cohort who were activated on the waiting list before 31st December $2011(N=5,239)$ were followed until 31st December 2013, to estimate the proportion transplanted with a kidney alone or kidney plus pancreas within two years of inclusion on the waiting list.

\section{Exclusions}

Patients listed for multi-organ transplants other than pancreas were excluded as were those who were suspended for more than 30 days within 90 days of first activation. The latter avoided any potential bias from centres that may activate patients on the transplant list and then immediately suspend them before more permanent activation at a later date after more formal medical assessment of the patient's fitness.

\section{Data analysed}

Information on start date of renal replacement therapy and relevant patient level data including age (grouped as 18-29, 30$39,40-49,50-59,60-64)$, gender, ethnicity (White, non-White, missing) and (primary renal diagnosis (PRD) classified as: patient with diabetes, patient without diabetes, missing) came from the UKRR. The date of activation on the kidney transplant waiting list, date of transplantation, or both came from the UK Transplant Registry held by the Organ Donation and Transplantation Directorate of NHS Blood and Transplant.

\section{Statistical methods}

A logistic regression model was developed to identify the influence of patient specific variables including age, gender, ethnicity and $\mathrm{PRD}$, on the probability of access to the transplant list and receipt of a transplant once on the waiting list. After adjusting for patient specific variables, the percentage of patients activated on the transplant list and the percentage of patients on the waiting list who achieved a transplant in each centre was determined. The overall effect of the centre associated with each analysis was assessed by including renal centre as a random effect in the risk-adjusted logistic regression model. The extent of variation between centres was determined by using a log likelihood ratio test that provided the change in the value of $-2 \log L$ on inclusion of the random centre effect. SAS 9.4 was used for analyses; a $p$ value of less than $5 \%$ was considered significant.

To analyse access to the transplant list, the proportion of incident patients with end stage renal disease in each centre who were subsequently activated on the waiting list within two years of starting renal replacement therapy (RRT) was identified. All patients who achieved live donor transplantation without prior activation on the national transplant waiting list were assumed to have been activated for the purposes of this analysis. Time to activation on the waiting list was defined as the interval between the start of RRT and the date of activation on the waiting list. Patients achieving pre-emptive deceased donor transplantation were considered to have been activated on the same day as starting RRT i.e. a time to activation of zero days. Patients achieving preemptive live donor transplantation without prior activation on the national transplant list were considered to have been 'active' on the list for an arbitrary time of six months. This was to take into account an average of six months required by most centres to complete live donor fitness evaluation and hence the likelihood that the intended recipient was considered fit for transplantation (and by inference suitable to be active on the waiting list) for that duration. This was done to account for different centre practices with regard to listing patients on the deceased donor list prior to receiving a living donor transplant.

The median time to activation was estimated from the KaplanMeier plot for patients at each renal centre, with the event as the date of activation and censoring at death or on 31st December 2012, whichever was earlier. Data from patients who did not achieve activation were included in the calculation of median times using this method, thus providing a meaningful estimate of the true time to activation. Including only those patients activated would produce 
a biased estimate. The overall centre effect associated with time to activation was calculated by including renal centre as a variable in a risk-adjusted Cox regression model.

To analyse the difference between centres in renal transplantation once listed, the percentage of patients activated on the waiting list who received a renal transplant within two years of being activated was estimated (conversion efficiency). The conversion efficiency for receiving a transplant from a donor after brainstem death or a donor after cardiac death/living kidney donor was analysed separately. Receipt of a kidney from a donor after brainstem death was predominantly influenced by national allocation policy, whereas receipt from a donor after cardiac death/live donor kidney was much more dependent on local transplant centre practices. For the cohort under consideration, donor after cardiac death transplantation was predominantly a locally managed service.

Funnel plots are used to present the results for each outcome of interest, providing a visual comparison of each centre's performance compared with its peers. Where relevant, the funnel plots are adjusted for patient specific variables influencing that outcome. The solid black straight line in each funnel plot shows the overall average together with the $95 \%$ and $99.8 \%$ confidence intervals, which correspond to two and three standard deviations from the mean. Each point on the plot represents one renal centre. With 71 centres included, for each outcome of interest, three centres would be predicted to fall between the $95 \%$ and $99.8 \%$ confidence intervals and no centre should fall outside the $99.8 \%$ confidence interval. Centres $(n=3)$ with fewer than 10 patients activated on the waiting list are not included in the funnel plots.

The analysis methodology described above is identical to a previous independent peer reviewed publication [5].

\section{Results}

The results of the logistic regression model analysis of patient characteristics influencing access to the waiting list are presented in table 11.1. Ethnicity data were missing for $11 \%$ of patients and PRD for $6 \%$ of patients.

Tables 11.2 and 11.3 show the results of the logistic regression analysis of factors influencing the likelihood of receiving a transplant from a donor after brainstem death and the analysis of factors influencing receipt of a transplant from a donor after cardiac death or a living kidney donor. Ethnicity data were missing for $8.1 \%$ of patients and PRD for $6.1 \%$ of patients (table 11.3).

A patient starting dialysis in a non-transplanting renal centre was less likely to be registered for transplantation (OR 0.74, 95\% CI 0.68-0.81) or receive a transplant from a donor after cardiac death or a living kidney donor (OR $0.75,95 \%$ CI $0.67-0.84$ ) compared with patients managed in transplanting renal centres. Once registered for kidney transplantation, patients in both transplanting and non-transplanting renal centres had an equal chance of receiving a transplant from a donor after brainstem death (OR 0.93, 95\% CI 0.78-1.10).

After adjusting for patient specific variables that were shown to influence outcome (age, ethnicity, gender, PRD), significant centre effects were identified for the probability of being activated on the waiting list (figure 11.1, table 11.4) (change in $-2 \log L=188.6$, df (degrees of freedom $)=1, p<0.0001)$.

After adjustment for patient variables, significant centre differences were seen in the probability of receiving a renal transplant from a donor after brain stem death (figure 11.2, table 11.5) (change in $-2 \log \mathrm{L}=13.3, \mathrm{df}=1, p=0.0003)$ or a donor after cardiac death/living kidney donor (figure 11.3, table 11.5) (change in $-2 \log \mathrm{L}=136.1, \quad \mathrm{df}=1$,

Table 11.1. Patient factors influencing activation on the national kidney transplant waiting list within two years of RRT start

\begin{tabular}{|c|c|c|c|c|c|}
\hline Factor & $\begin{array}{c}\text { Category } \\
\text { (at baseline) }\end{array}$ & $\begin{array}{c}\text { Patients } \\
N(\%)\end{array}$ & $\begin{array}{l}\text { Odds } \\
\text { ratio }\end{array}$ & $95 \%$ CI & $P$ value \\
\hline Age & $\begin{array}{c}(18-29) \\
30-39 \\
40-49 \\
50-59 \\
60-64\end{array}$ & $\begin{array}{cc}899 & (8.9) \\
1,425 & (14.1) \\
2,400 & (23.8) \\
3,239 & (32.1) \\
2,116 & (21.0)\end{array}$ & $\begin{array}{c}1 \\
1.06 \\
0.70 \\
0.36 \\
0.20\end{array}$ & $\begin{array}{c}\text { ref } \\
0.88-1.27 \\
0.59-0.83 \\
0.31-0.43 \\
0.17-0.24\end{array}$ & $\begin{aligned} & \mathrm{n} / \mathrm{a} \\
& 0.57 \\
< & 0.0001 \\
< & 0.0001 \\
< & 0.0001\end{aligned}$ \\
\hline Gender & $\begin{array}{l}\text { (Male) } \\
\text { Female }\end{array}$ & $\begin{array}{l}6,086(60.4) \\
3,993(39.6)\end{array}$ & $\begin{array}{c}1 \\
0.95\end{array}$ & $\begin{array}{c}\text { ref } \\
0.88-1.04\end{array}$ & $\begin{array}{c}\mathrm{n} / \mathrm{a} \\
0.28\end{array}$ \\
\hline PRD & $\begin{array}{c}\text { (Non-diabetic) } \\
\text { Diabetic } \\
\text { Missing }\end{array}$ & $\begin{array}{c}7,017(69.6) \\
2,455(24.4) \\
607(6.0)\end{array}$ & $\begin{array}{c}1 \\
0.44 \\
0.84\end{array}$ & $\begin{array}{c}\text { ref } \\
0.40-0.49 \\
0.71-1.00\end{array}$ & $\begin{array}{c}\mathrm{n} / \mathrm{a} \\
<0.0001 \\
0.06\end{array}$ \\
\hline
\end{tabular}

ref - reference category, n/a - not applicable 
Table 11.2. Patient factors affecting the probability of receiving a transplant from a donor after brainstem death within two years of registration on the national kidney transplant waiting list

\begin{tabular}{|c|c|c|c|c|c|}
\hline Factor & $\begin{array}{c}\text { Category } \\
\text { (at baseline) }\end{array}$ & $\begin{array}{c}\text { Patients } \\
N(\%)\end{array}$ & $\begin{array}{l}\text { Odds } \\
\text { ratio }\end{array}$ & $95 \% \mathrm{CI}$ & $P$ value \\
\hline Age & $\begin{array}{c}(18-29) \\
30-39 \\
40-49 \\
50-59 \\
60-64\end{array}$ & $\begin{array}{r}646(12.3) \\
1,014(19.4) \\
1,457(27.8) \\
1,444(27.6) \\
678(12.9)\end{array}$ & $\begin{array}{c}1 \\
1.05 \\
0.78 \\
0.40 \\
0.23\end{array}$ & $\begin{array}{c}\text { ref } \\
0.80-1.38 \\
0.60-1.01 \\
0.30-0.54 \\
0.15-0.35\end{array}$ & $\begin{aligned} & \mathrm{n} / \mathrm{a} \\
& 0.7 \\
& 0.06 \\
< & 0.0001 \\
< & 0.0001\end{aligned}$ \\
\hline Ethnicity & $\begin{array}{l}\text { (White) } \\
\text { Non-White } \\
\text { Missing }\end{array}$ & $\begin{array}{c}3,639(69.5) \\
1,176(22.5) \\
424(8.1)\end{array}$ & $\begin{array}{c}1 \\
0.65 \\
1.05\end{array}$ & $\begin{array}{c}\text { ref } \\
0.52-0.81 \\
0.78-1.40\end{array}$ & $\begin{array}{l}\mathrm{n} / \mathrm{a} \\
0.0001 \\
0.7\end{array}$ \\
\hline Gender & $\begin{array}{l}\text { (Male) } \\
\text { Female }\end{array}$ & $\begin{array}{l}3,180(60.7) \\
2,059(39.3)\end{array}$ & $\begin{array}{c}1 \\
1.32\end{array}$ & $\begin{array}{c}\text { ref } \\
1.11-1.56\end{array}$ & $\begin{array}{c}\mathrm{n} / \mathrm{a} \\
0.002\end{array}$ \\
\hline PRD & $\begin{array}{c}\text { (Non-diabetic) } \\
\text { Diabetic } \\
\text { Missing }\end{array}$ & $\begin{array}{c}4,045(77.2) \\
874(16.7) \\
320(6.1)\end{array}$ & $\begin{array}{c}1 \\
3.79 \\
1.04\end{array}$ & $\begin{array}{c}\text { ref } \\
3.13-4.57 \\
0.71-1.52\end{array}$ & $\begin{array}{c}\mathrm{n} / \mathrm{a} \\
<0.0001 \\
0.8\end{array}$ \\
\hline
\end{tabular}

ref - reference category, n/a - not applicable

$p<0.0001)$. As shown, several centres fall outside the $95 \%$ and $99.8 \%$ confidence intervals.

Figure 11.4 and table 11.6 show the unadjusted median time taken to activate patients on the transplant list for each renal centre.

The funnel plot is based on the assumption of an exponential distribution for time to activation. Although this assumption is broadly consistent with the data, the model based estimate of the national median was greater than that observed. This leads to an unusually large number of centres falling outside the lower $99.8 \%$ confidence limit for this national rate and perhaps too few occurring outside the upper limit. However, the plot highlights those centres that have significantly longer time to activation but small numbers on the waiting list. The Cox model giving a risk-adjusted analysis of time to activation identified a significant effect of centre variation (change in $-2 \log \mathrm{L}=372.7, \mathrm{df}=70, p<0.0001$ ). In general, centres with the longest unadjusted waiting times also had the longest risk-adjusted waiting times. The three centres lying outside the upper $99.8 \%$ confidence limit all had hazard ratios that indicated a significant delay in the

Table 11.3. Patient factors affecting the probability of receiving a transplant from a donor after cardiac death or living kidney donor within two years of registration on the national kidney transplant waiting list

\begin{tabular}{|c|c|c|c|c|c|}
\hline Factor & $\begin{array}{c}\text { Category } \\
\text { (at baseline) }\end{array}$ & $\begin{array}{c}\text { Patients } \\
N(\%)\end{array}$ & $\begin{array}{l}\text { Odds } \\
\text { ratio }\end{array}$ & $95 \% \mathrm{CI}$ & $P$ value \\
\hline Age & $\begin{array}{c}(18-29) \\
30-39 \\
40-49 \\
50-59 \\
60-64\end{array}$ & $\begin{array}{r}646(12.3) \\
1,014(19.4) \\
1,457(27.8) \\
1,444(27.6) \\
678(12.9)\end{array}$ & $\begin{array}{c}1 \\
0.64 \\
0.57 \\
0.51 \\
0.5\end{array}$ & $\begin{array}{c}\text { ref } \\
0.53-0.79 \\
0.47-0.70 \\
0.42-0.62 \\
0.40-0.63\end{array}$ & $\begin{aligned} & \mathrm{n} / \mathrm{a} \\
< & 0.0001 \\
< & 0.0001 \\
< & 0.0001 \\
< & 0.0001\end{aligned}$ \\
\hline Ethnicity & $\begin{array}{c}\text { (White) } \\
\text { Non-White } \\
\text { Missing }\end{array}$ & $\begin{array}{c}3,639(69.5) \\
1,176(22.5) \\
424(8.1)\end{array}$ & $\begin{array}{c}1 \\
0.51 \\
0.54\end{array}$ & $\begin{array}{c}\text { ref } \\
0.44-0.59 \\
0.43-0.67\end{array}$ & $\begin{array}{c}\mathrm{n} / \mathrm{a} \\
<0.0001 \\
<0.0001\end{array}$ \\
\hline Gender & $\begin{array}{l}\text { (Male) } \\
\text { Female }\end{array}$ & $\begin{array}{l}3,180(60.7) \\
2,059(39.3)\end{array}$ & $\begin{array}{c}1 \\
0.77\end{array}$ & $\begin{array}{c}\text { ref } \\
0.68-0.86\end{array}$ & $\begin{array}{c}\mathrm{n} / \mathrm{a} \\
<0.0001\end{array}$ \\
\hline PRD & $\begin{array}{c}\text { (Non-diabetic) } \\
\text { Diabetic } \\
\text { Missing }\end{array}$ & $\begin{array}{c}4,045(77.2) \\
874(16.7) \\
320(6.1)\end{array}$ & $\begin{array}{c}1 \\
0.37 \\
1.42\end{array}$ & $\begin{array}{c}\text { ref } \\
0.31-0.44 \\
1.13-1.80\end{array}$ & $\begin{array}{c}\mathrm{n} / \mathrm{a} \\
<0.0001 \\
0.003\end{array}$ \\
\hline
\end{tabular}

ref - reference category, n/a - not applicable 


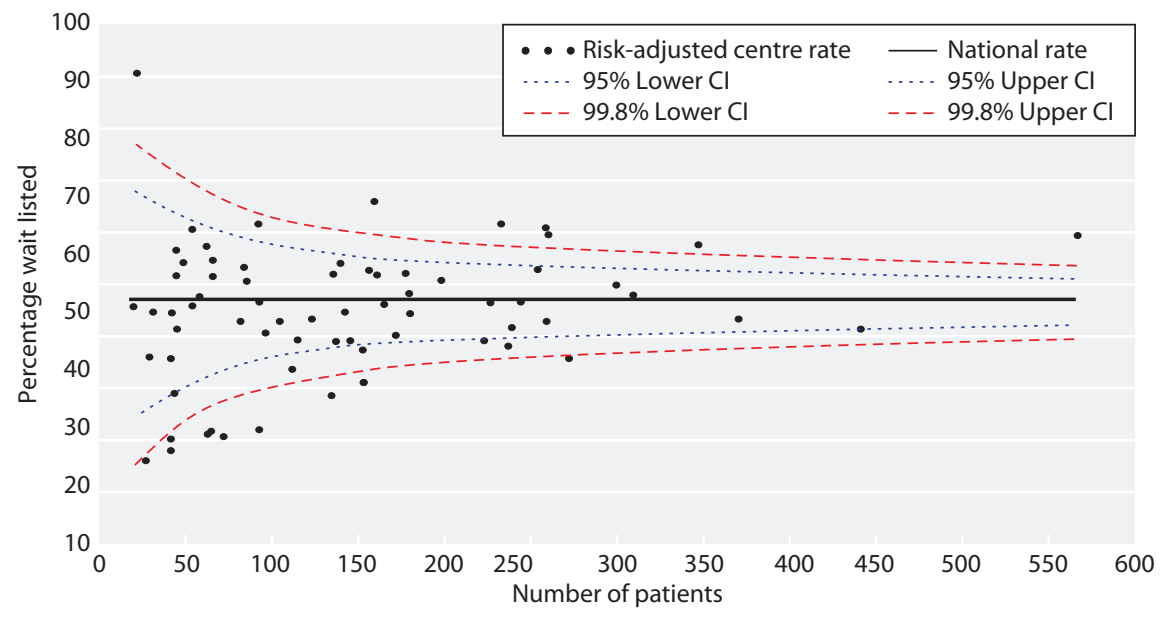

Fig. 11.1. Percentage of patients waitlisted for a kidney transplant by renal centre, prior to or within two years of starting dialysis (centres with $<10$ patients excluded)

Table 11.4. Percentage of patients wait-listed for a kidney transplant by renal centre, prior to or within two years of starting dialysis

\begin{tabular}{|c|c|c|c|c|c|c|c|c|c|}
\hline \multirow[b]{2}{*}{ Centre } & \multirow{2}{*}{$\begin{array}{c}\text { RRT } \\
N\end{array}$} & \multirow{2}{*}{$\begin{array}{c}\text { Registrations } \\
\qquad N\end{array}$} & \multicolumn{2}{|c|}{$\%$ wait listed } & \multirow[b]{2}{*}{ Centre } & \multirow{2}{*}{$\begin{array}{c}\text { RRT } \\
N\end{array}$} & \multirow{2}{*}{$\begin{array}{c}\text { Registrations } \\
N\end{array}$} & \multicolumn{2}{|c|}{$\%$ wait listed } \\
\hline & & & Unadjusted & Risk-adjusted & & & & Unadjusted & Risk-adjusted \\
\hline England & & & & & Plymth & 96 & 64 & 66.7 & 65.9 \\
\hline B Heart & 143 & 65 & 45.5 & 44.4 & Ports & 231 & 154 & 66.7 & 65.1 \\
\hline $\mathrm{B}$ QEH & 370 & 181 & 48.9 & 48.3 & Prestn & 221 & 98 & 44.3 & 44.4 \\
\hline Basldn & 37 & 10 & 27.0 & 25.2 & Redng & 157 & 109 & 69.4 & 68.8 \\
\hline Bradfd & 111 & 51 & 45.9 & 44.7 & Salford & 252 & 145 & 57.5 & 56.7 \\
\hline Brightn & 135 & 62 & 45.9 & 44.3 & Sheff & 237 & 114 & 48.1 & 46.7 \\
\hline Bristol & 257 & 130 & 50.6 & 47.7 & Shrew & 61 & 16 & 26.2 & 28.4 \\
\hline Camb & 153 & 91 & 59.5 & 56.8 & Stevng & 177 & 97 & 54.8 & 52.5 \\
\hline Carlis & 41 & 27 & 65.9 & 60.4 & Sthend & 44 & 25 & 56.8 & 58.2 \\
\hline Carsh & 270 & 114 & 42.2 & 41.3 & Stoke & 120 & 60 & 50.0 & 48.3 \\
\hline Chelms & 62 & 35 & 56.5 & 58.4 & Sund & 101 & 50 & 49.5 & 47.8 \\
\hline Colchr & 41 & 23 & 56.1 & 55.9 & Truro & 58 & 35 & 60.3 & 60.9 \\
\hline Covnt & 169 & 79 & 46.7 & 45.3 & Wirral & 89 & 26 & 29.2 & 28.7 \\
\hline Derby & 108 & 41 & 38.0 & 39.4 & Wolve & 131 & 47 & 35.9 & 34.7 \\
\hline Donc & 50 & 30 & 60.0 & 64.2 & York & 50 & 27 & 54.0 & 50.9 \\
\hline Dorset & 81 & 47 & 58.0 & 57.4 & N Ireland & & & & \\
\hline Dudley & 69 & 19 & 27.5 & 27.5 & Antrim & 40 & 14 & 35.0 & 35.0 \\
\hline Exeter & 149 & 62 & 41.6 & 42.9 & Belfast & 93 & 43 & 46.2 & 45.5 \\
\hline Glouc & 82 & 45 & 54.9 & 54.7 & Newry & 28 & 13 & 46.4 & 49.5 \\
\hline Hull & 139 & 60 & 43.2 & 49.5 & Ulster & 16 & 7 & 43.8 & 50.4 \\
\hline Ipswi & 54 & 30 & 55.6 & 52.2 & West NI & 38 & 21 & 55.3 & 49.2 \\
\hline Kent & 175 & 103 & 58.9 & 56.2 & Scotland & & & & \\
\hline L Barts & 441 & 206 & 46.7 & 46.4 & Abrdn & 88 & 46 & 52.3 & 64.9 \\
\hline L Guys & 298 & 168 & 56.4 & 54.2 & Airdrie & 78 & 28 & 35.9 & 47.7 \\
\hline L Kings & 234 & 101 & 43.2 & 43.3 & D\&Gall & 18 & 10 & 55.6 & 91.6 \\
\hline L Rfree & 308 & 165 & 53.6 & 52.2 & Dundee & 62 & 25 & 40.3 & 55.6 \\
\hline L St.G & 158 & 91 & 57.6 & 55.9 & Edinb & 137 & 63 & 46.0 & 58.1 \\
\hline L West & 568 & 346 & 60.9 & 62.9 & Glasgw & 257 & 127 & 49.4 & 64.3 \\
\hline Leeds & 225 & 120 & 53.3 & 51.4 & Inverns & 37 & 15 & 40.5 & 41.3 \\
\hline Leic & 346 & 216 & 62.4 & 61.4 & Klmarnk & 49 & 13 & 26.5 & 37.8 \\
\hline Liv Ain & 60 & 16 & 26.7 & 28.1 & Krkcldy & 41 & 14 & 34.1 & 46.4 \\
\hline Liv Roy & 177 & 96 & 54.2 & 49.3 & Wales & & & & \\
\hline M RI & 246 & 135 & 54.9 & 51.6 & Bangor & 37 & 9 & 24.3 & 27.3 \\
\hline Middlbr & 132 & 79 & 59.8 & 56.1 & Cardff & 243 & 128 & 52.7 & 51.4 \\
\hline Newc & 162 & 85 & 52.5 & 50.9 & Clwyd & 22 & 5 & 22.7 & 23.4 \\
\hline Norwch & 89 & 46 & 51.7 & 51.2 & Swanse & 150 & 56 & 37.3 & 37.1 \\
\hline Nottm & 196 & 115 & 58.7 & 55.1 & Wrexm & 25 & 11 & 44.0 & 41.2 \\
\hline Oxford & 259 & 170 & 65.6 & 63.0 & & & & & \\
\hline
\end{tabular}




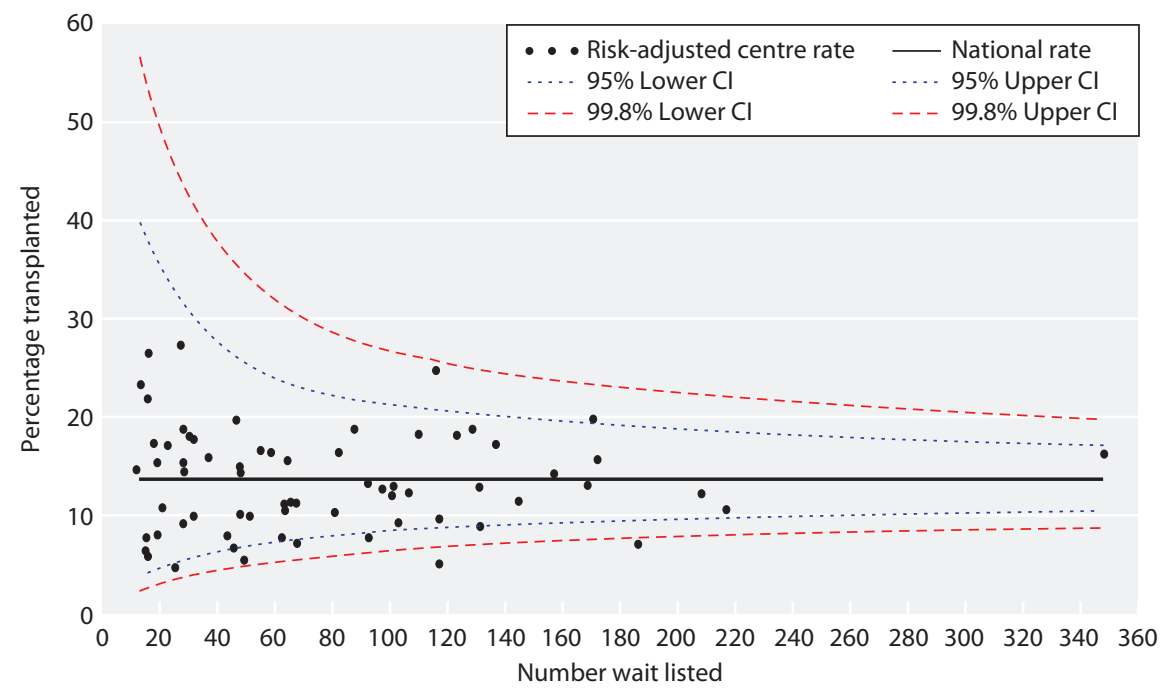

Fig. 11.2. Percentage of patients receiving a transplant from a donor after brainstem death by renal centre, within two years of transplant waiting list registration (centres with $<10$ patients excluded) chance of wait-listing compared with a baseline centre that had a median time comparable to the national median.

\section{Discussion}

\section{Centre variation}

The analyses performed within this report highlight a significant centre effect in relation to the proportion of patients wait-listed with nearly $20 \%$ of centres lying outside the lower 95\% confidence interval, and seven centres outside the lower $99.8 \%$ confidence interval, despite adjusting for a range of patient characteristics. Inter-centre differences are also noted in access to transplants from donors after cardiac death/living kidney donors with nine centres lying outside the lower $99.8 \%$ confidence interval.

Whilst both these outcomes are subject to individual centre practices and policies (which thus could be deemed a cause of the observed variation), one needs to interpret these results with caution as this study is limited by the lack comprehensive comorbidity data on all patients. Centres with higher prevalence rates of comorbidities would be expected to list proportionally fewer patients to reflect the fact that fewer patients are fit for transplantation. Additionally, it may take longer to activate patients in these centres due to the need for more intensive investigation and medical optimisation prior to transplantation. Indeed lack of comorbidity data limits definitive adjustment for case mix. Other patient level factors which this study also fails to adjust for include social deprivation which has been associated with reduced access to transplantation of a range of organs, as well as the impact of primary renal diagnoses (other than diabetes), health literacy and human leucocyte antigen (HLA) sensitisation. Additonally, this study has not analysed the interplay between factors such as social deprivation and ethnicity and whether the observed differences based on ethnicity are likely to persist after adjustment for social deprivation and varying comorbidity burden in different ethnic groups. In essence, the available dataset does not permit definitive adjustment for case mix.

The observation that a patient starting dialysis in a non-transplanting renal centre was less likely to be registered for transplantation or receive a transplant from a donor after cardiac death (or a living kidney donor) compared with patients managed in transplanting renal centres, has been a consistent finding in similar analyses by the UKRR over the last five years. The finding implies increasing distance from the transplanting centre diminishes access to treatment. Despite the inability to conclusively adjust for case mix in our analyses, the consistent finding in the same direction, suggests centre practice patterns rather than patient dependant variables may explain this finding. Further detailed analyses to understand the reasons for such variability is currently being undertaken as part of the Access to Transplant and Transplant Outcome Measures (ATTOM) study. Once registered for kidney transplantation, patients in both transplanting and non-transplanting renal centres had an equal chance of receiving a transplant from a donor after brainstem death. This is reassuring as organ allocation is subject to the national allocation algorithm which one would expect to allocate organs equitably. 
Table 11.5. Percentage of patients receiving a transplant, by donor type and renal centre, within two years of transplant waiting list registration

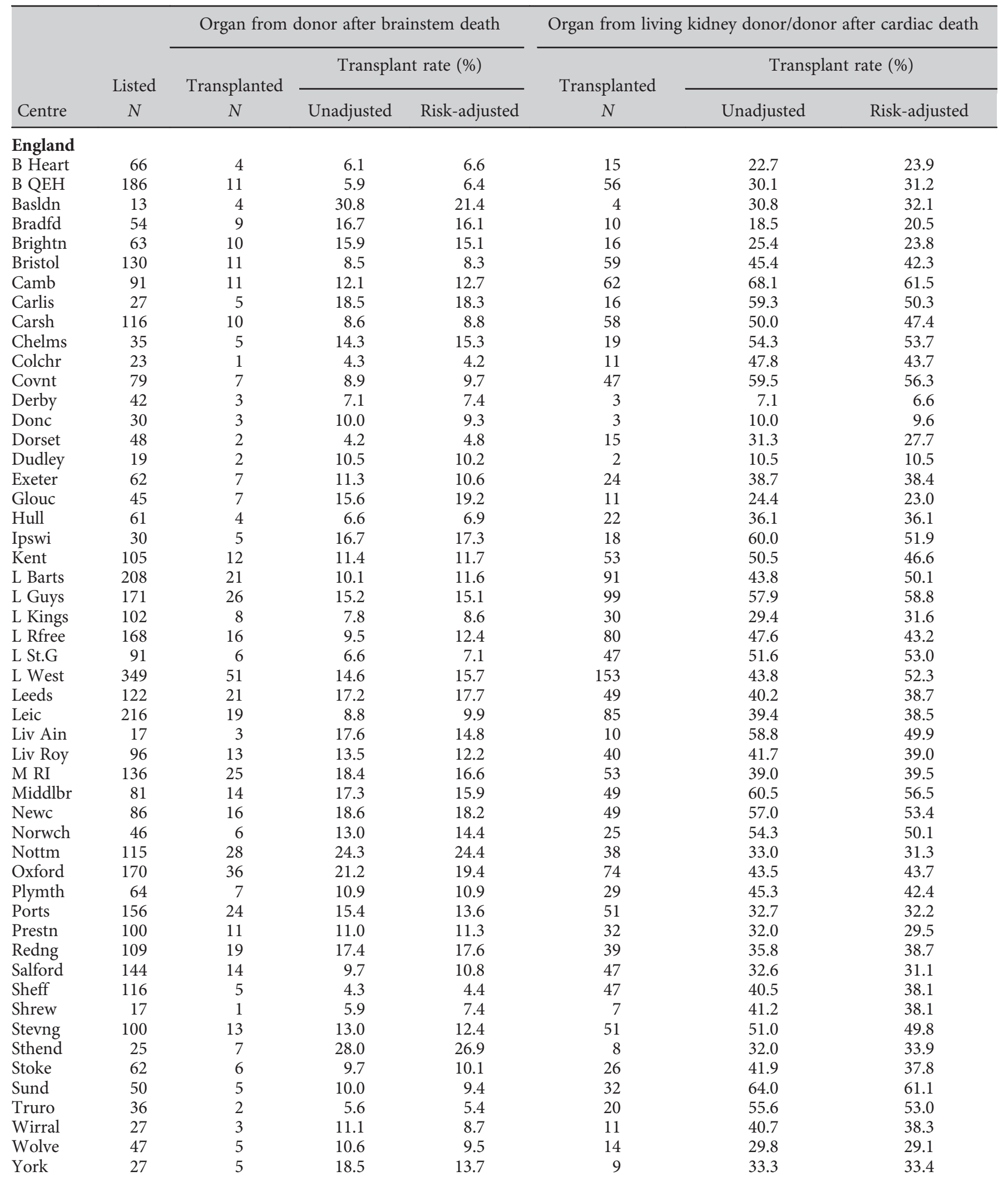


Table 11.5. Continued

\begin{tabular}{|c|c|c|c|c|c|c|c|}
\hline \multirow{2}{*}{ Centre } & \multirow{2}{*}{$\begin{array}{l}\text { Listed } \\
\quad N\end{array}$} & \multicolumn{3}{|c|}{ Organ from donor after brainstem death } & \multicolumn{3}{|c|}{ Organ from living kidney donor/donor after cardiac death } \\
\hline & & $\begin{array}{c}\text { Transplanted } \\
N\end{array}$ & \multicolumn{2}{|c|}{ Transplant rate $(\%)$} & $\begin{array}{c}\text { Transplanted } \\
N\end{array}$ & \multicolumn{2}{|c|}{ Transplant rate $(\%)$} \\
\hline \multicolumn{8}{|l|}{ N Ireland } \\
\hline Antrim & 14 & 1 & 7.1 & 7.0 & 5 & 35.7 & 30.5 \\
\hline Ulster & 7 & 0 & 0.0 & 0.0 & 1 & 14.3 & 14.6 \\
\hline West NI & 21 & 3 & 14.3 & 16.5 & 5 & 23.8 & 20.5 \\
\hline \multicolumn{8}{|l|}{ Scotland } \\
\hline Abrdn & 46 & 7 & 15.2 & 13.8 & 12 & 26.1 & 31.7 \\
\hline Airdrie & 29 & 7 & 24.1 & 17.5 & 5 & 17.2 & 23.0 \\
\hline D\&Gall & 10 & 2 & 20.0 & 13.9 & 1 & 10.0 & 17.5 \\
\hline Klmarnk & 14 & 4 & 28.6 & 26.1 & 1 & 7.1 & 9.0 \\
\hline Krkcldy & 14 & 1 & 7.1 & 5.4 & 2 & 14.3 & 19.9 \\
\hline \multicolumn{8}{|l|}{ Wales } \\
\hline Bangor & 9 & 5 & 55.6 & 70.1 & 2 & 22.2 & 20.4 \\
\hline Cardff & 128 & 24 & 18.8 & 18.2 & 49 & 38.3 & 35.4 \\
\hline Clwyd & 5 & 0 & 0.0 & 0.0 & 2 & 40.0 & 33.3 \\
\hline Swanse & 57 & 11 & 19.3 & 15.9 & 28 & 49.1 & 48.2 \\
\hline Wrexm & 11 & 3 & 27.3 & 22.9 & 4 & 36.4 & 31.3 \\
\hline
\end{tabular}

Patient level factors affecting access

The finding that certain patient variables, such as increasing age, have a negative association with access to transplantation was not unexpected as the risk-benefit ratio of receiving a renal transplant alters with age. Increased comorbidity burden in older patients may require more intensive time consuming investigations prior to listing and may also deem them unsuitable in some cases. In this study 'non-White' ethnicity was negatively associated with access to transplantation and receiving a kidney once listed (from a donor after brainstem death, and from a living kidney donor/donor after cardiac death). This may partly be explained by the importance given to HLA matching in the national allocation protocol which may have favoured a predominantly white donor pool being matched with white recipients and also the widely acknowledged lack of donors from ethnic minorities contributing to the

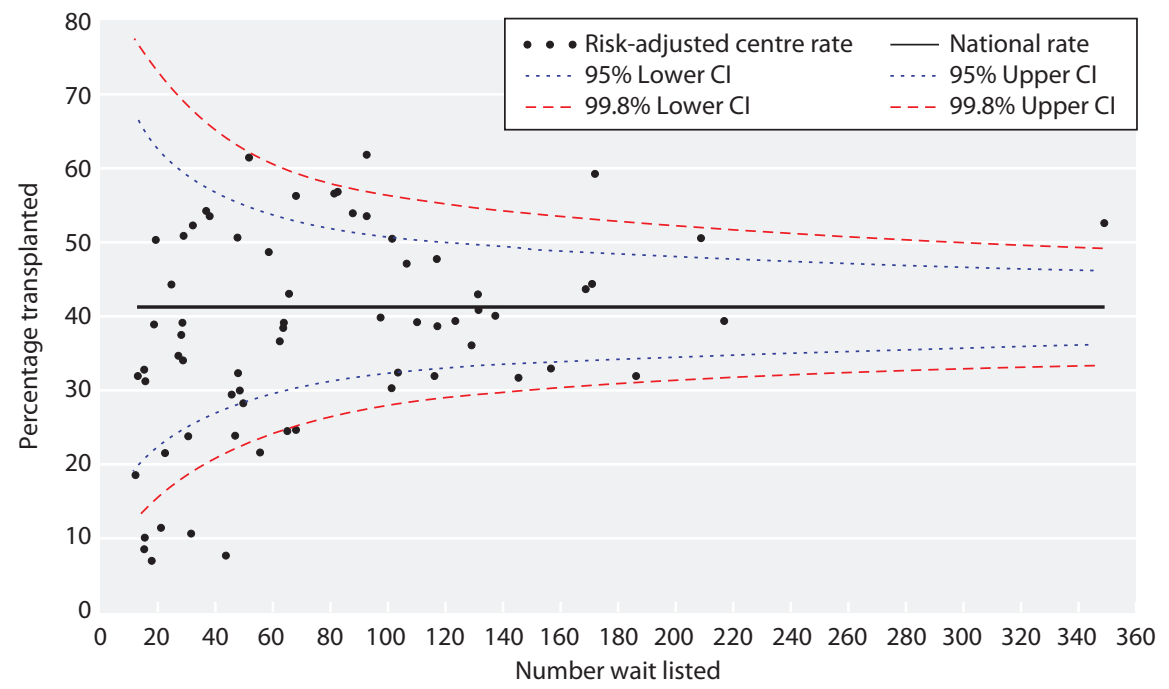

Fig. 11.3. Percentage of patients receiving a transplant from a living kidney donor/ donor after cardiac death by renal centre, within two years of transplant waiting list registration (centres with $<10$ patients excluded) 


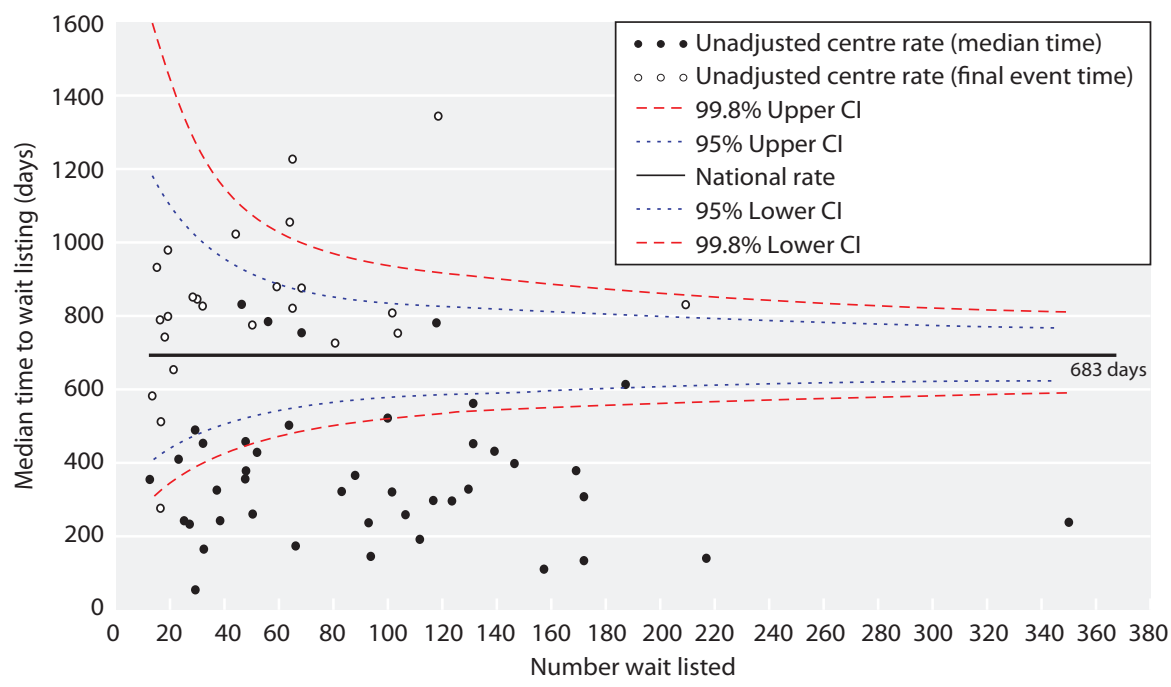

Fig. 11.4. Median time to wait listing for a kidney transplant, by renal centre (centres with $<10$ patients excluded)

Table 11.6. Median time to wait listing for a kidney transplant, by renal centre (censoring at the earliest of death or 31st December 2012)

\begin{tabular}{|c|c|c|c|c|c|c|c|}
\hline Centre & $\begin{array}{c}\text { RRT } \\
N\end{array}$ & $\begin{array}{c}\text { Registrations } \\
\qquad N\end{array}$ & $\begin{array}{l}\text { Median time to listing } \\
\text { (days) }\end{array}$ & Centre & $\begin{array}{l}\text { RRT } \\
N\end{array}$ & $\begin{array}{c}\text { Registrations } \\
N\end{array}$ & $\begin{array}{l}\text { Median time to listing } \\
\text { (days) }\end{array}$ \\
\hline England & & & & Plymth & 96 & 64 & 157 \\
\hline B Heart & 143 & 66 & $867^{*}$ & Ports & 231 & 156 & 91 \\
\hline B QEH & 370 & 186 & 598 & Prestn & 221 & 100 & $797^{*}$ \\
\hline Basldn & 37 & 13 & $923^{*}$ & Redng & 157 & 110 & 174 \\
\hline Bradfd & 111 & 54 & 773 & Salford & 252 & 145 & 380 \\
\hline Brightn & 135 & 63 & $811^{*}$ & Sheff & 237 & 116 & 769 \\
\hline Bristol & 257 & 130 & 436 & Shrew & 61 & 17 & $787^{*}$ \\
\hline Camb & 153 & 92 & 128 & Stevng & 177 & 100 & 302 \\
\hline Carlis & 41 & 27 & 36 & Sthend & 44 & 25 & 215 \\
\hline Carsh & 270 & 117 & $1,345^{*}$ & Stoke & 120 & 62 & 488 \\
\hline Chelms & 62 & 35 & 309 & Sund & 101 & 50 & 413 \\
\hline Colchr & 41 & 23 & 226 & Truro & 58 & 36 & 223 \\
\hline Covnt & 169 & 79 & $712^{*}$ & Wirral & 89 & 27 & $835^{*}$ \\
\hline Derby & 108 & 42 & $1,017^{*}$ & Wolve & 131 & 48 & $765^{*}$ \\
\hline Donc & 50 & 30 & 147 & York & 50 & 27 & 472 \\
\hline Dorset & 81 & 48 & 243 & N Ireland & & & \\
\hline Dudley & 69 & 19 & $641^{*}$ & Antrim & 40 & 14 & $495^{*}$ \\
\hline Exeter & 149 & 63 & $1,225^{*}$ & Belfast & 93 & 44 & 821 \\
\hline Glouc & 82 & 45 & 340 & Newry & 28 & 13 & $683^{*}$ \\
\hline Hull & 139 & 62 & $1,049^{*}$ & Ulster & 16 & 7 & $180^{*}$ \\
\hline Ipswi & 54 & 30 & 438 & West NI & 38 & 21 & 397 \\
\hline Kent & 175 & 105 & 240 & Scotland & & & \\
\hline L Barts & 441 & 208 & $816^{*}$ & Abrdn & 88 & 46 & 365 \\
\hline L Guys & 298 & 171 & 291 & Airdrie & 78 & 30 & $816^{*}$ \\
\hline L Kings & 234 & 102 & $742^{*}$ & D\&Gall & 18 & 10 & 335 \\
\hline L Rfree & 308 & 168 & 364 & Dundee & 62 & 26 & $838^{*}$ \\
\hline L St.G & 158 & 91 & 216 & Edinb & 137 & 66 & 741 \\
\hline L West & 568 & 350 & 220 & Glasgw & 257 & 130 & 548 \\
\hline Leeds & 225 & 122 & 281 & Inverns & 37 & 16 & $735^{*}$ \\
\hline Leic & 346 & 216 & 116 & Klmarnk & 49 & 14 & $779^{*}$ \\
\hline Liv Ain & 60 & 17 & $967^{*}$ & Krkcldy & 41 & 14 & $258^{*}$ \\
\hline Liv Roy & 177 & 98 & 508 & Wales & & & \\
\hline M RI & 246 & 138 & 416 & Bangor & 37 & 9 & $716^{*}$ \\
\hline Middlbr & 132 & 81 & 304 & Cardfff & 243 & 128 & 311 \\
\hline Newc & 162 & 86 & 348 & Clwyd & 22 & 5 & $682^{*}$ \\
\hline Norwch & 89 & 46 & 440 & Swanse & 150 & 57 & $870^{*}$ \\
\hline Nottm & 196 & 115 & 280 & Wrexm & 25 & 11 & $564^{*}$ \\
\hline Oxford & 259 & 171 & 115 & & & & \\
\hline
\end{tabular}

${ }^{*}$ Results in bold italics are final event times as median times could not be estimated 
donor pool. Lack of adjustment for social deprivation may also explain some of this association, as Udayaraj has previously published data showing that adjusting for social deprivation may partly explain the reduced access to transplantation seen in ethnic groups [6].

Diabetes was also seen to affect wait-listing adversely although this is not surprising as many would be subject to additional diabetic complications and increased cardiovascular risk that would need to be managed. The higher proportion of patients with diabetes receiving a transplant corresponds to an increase in the number of simultaneous kidney-pancreas transplants during the study period, as the allocation algorithm prioritised dual organ recipients.

When interpreting the analyses in this chapter it is important to consider the potential impact of missing data on the results. Missing data occurs as a result of either a renal centre failing to complete relevant fields on their renal IT system or a failure to extract this data. Missing data may not be at random; sicker patients may die more quickly, allowing inadequate time for their physician to enter relevant comorbidity data. The very process of working up and listing a patient makes it less likely that data will be missing. It is therefore perhaps not surprising that patients activated on the national kidney transplant waiting list are more likely to have ethnicity and PRD data reported $(p<0.0001)$ (table 11.1).

The UKRR is collaborating with other researchers in the National Institute for Health Research (NIHR) funded ATTOM research project to study access to kidney transplantation in greater detail. This will allow those practices identified in the better performing centres to be disseminated to other centres, thereby facilitating equity of access to transplantation across the UK.

\section{Conclusions}

This study highlights the persistence of significant centre variation in access to transplantation with respect to the proportion of patients listed and the time taken to activate suitable patients, even after correction for available relevant patient related variables. Significant differences exist between transplanting and nontransplanting centres, with increasing age, non-White ethnicity and diabetes showing a negative association in terms of accessing the transplant wait-list.

Conflicts of interest: none

\section{References}

1 Wolfe RA, Ashby VB, Milford EL, Ojo AO, Ettenger RE, Agodoa LY, Held PJ, Port FK. Comparison of mortality in all patients on dialysis, patients on dialysis awaiting transplantation, and recipients of a first cadaveric transplant. N Engl J Medicine 1999;341(23):1725-30

2 Pinson CW, Feurer ID, Payne JL, Wise PE, Shockley S, Speroff T. Health related quality of life after different types of solid organ transplantation. Ann Surg 2000;232(4):597-607

- 3 Sureshkumar KK, Patel BM, Markatos A, Nghiem DD, Marcus RJ. Quality of life after organ transplantation in type 1 diabetes with end stage renal disease. Clin Transplant 2006;20(1):19-25

$4 \mathrm{http} / /$ www.uktransplant.org.uk/ukt/about_transplants/organ_allocation/ kidney_(renal)/kidney_(renal).jsp

5 Variation between centres in access to renal transplantation in UK: longitudinal cohort study. Ravanan R, Udayaraj U, Ansell D, Collett D, Johnson R, O’Neill J, Tomson CR, Dudley CR. BMJ. 2010 Jul 20; 341:c3451. doi: 10.1136/bmj.c3451

6 Social deprivation, ethnicity, and access to the deceased donor kidney transplant waiting list in England and Wales. Udayaraj U, Ben-Shlomo Y, Roderick P, Casula A, Dudley C, Johnson R, Collett D, Ansell D, Tomson C, Caskey F. Transplantation. 2010 Aug 15;90(3):279-85. doi: 10.1097/TP.0b013e3181e346e3 